\title{
Intracavitary Brachytherapy in Cervical Carcinoma: The Role of F18-FDG- PET in Treatment Planning
}

Sofia Meregalli ${ }^{1}$, Luca Guerra ${ }^{2}$, Alessandra Zorz ${ }^{3}$, Elisa Bonetto ${ }^{1}$, Sarah Brenna ${ }^{1}$, Gianluca Montanari ${ }^{3}$, Elena De Ponti ${ }^{3}$, Cristina Messa ${ }^{2}$ and Gianstefano Gardani ${ }^{1}$

${ }^{1}$ Brachytherapy Unit and Radiation Oncology Department, San Gerardo Hospital, University of Milano-Bicocca, School of Medicine, Italy

${ }^{2}$ Nuclear Medicine Department, San Gerardo Hospital, University of Milano-Bicocca, School of Medicine, Italy

${ }^{3}$ Medical Physics Unit, San Gerardo Hospital, University of Milano-Bicocca, School of Medicine, Italy

\begin{abstract}
Objective: concomitant chemoirradiation with cisplatinum and intracavitary brachytherapy (BT) is the standard of care in patients with locally advanced cervix cancer. Treatment planning for BT provides for the use of three dimensional imaging, such as CT scan or MRI. Positron emission Tomography with $\left[{ }^{18} \mathrm{~F}\right]$ FDG currently used in staging and restaging of this malignancy, is an imaging modality that can aid in image- guided radiation treatment planning. The purpose of our feasibility study was to compare two tumour volumes during BT planning, the CT-based and PET/CT-based clinical target volume (CTVs), in order to evaluate the value of functional imaging in BT planning and if it could be related to a CT standard data set. Moreover a correlation with some clinical data after a median follow up of 47 months is reported.
\end{abstract}

Methods: From June 2007 to May 2010, thirteen women with advanced cervical carcinoma were enrolled into the study. All the patients had a pretreatment PET/CT for staging. All BT fractions have been planned by CT scan and, in the first (BT1) and in the fourth fraction (BT4), FDG-PET/CT was also employed. Two volumes (CTVs) were

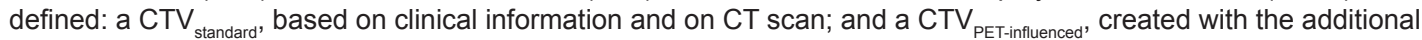
information brought by PET scan.

Results: We compared the dimension of the two volumes and the intersection of $\mathrm{CTV}_{\text {standard }}$ and CTV $\mathrm{PET}_{\text {-influenced }}$ at BT1 and BT4. A non-parametric sum rank test was used to determine the statistical significance for comparison of the two series of volumes (CTV standard $_{\text {and }}$ CTV $\mathrm{PET}_{\text {-infuenced }}$ at BT1 and BT4). All patients completed the protocol, but out of 26 attempts of double CTV definition, $^{\text {standard }}$, only for 21 cases a comparison between CTV $_{\text {standard }}$ and CTV $_{\text {PET-influenced }}$ was made. For two patients at the first BT fraction PET was negative. In the 21 valuable cases, considering both fractions together $\left(\mathrm{BT} 1\right.$ and BT4), the difference between $\mathrm{CTV}_{\text {standard }}(25.8 \pm 7.5 \mathrm{ml})$ and $\mathrm{CTV}_{\mathrm{PET} \text {-influenced }}(21.6 \pm 9.5 \mathrm{ml})$ was statistically significant $(p=0.01)$. In our small population the changes of $G T V_{P E T}$ was unpredictable with residual tracer uptake areas often located far from the applicator and not consistent with clinical evaluation and or CT information.

Conclusions: Even if the results of the study are preliminary because of the limited number of patients, our data suggests that PET scan cannot be used to define target volume in BT plan as the only source of information. It could be necessary an integration preferably with MRI for much more individualized brachytherapy treatment.

Keywords: Brachytherapy; Cervical carcinoma; PET/CT treatment planning

\section{Introduction}

Concomitant chemo-radiation with cisplatinum and intracavitary brachytherapy (BT) is the standard of care in patients with locally advanced cervix cancer [1-4]. The knowledge of the real tumour size is an important prognostic factor for the outcome of the patient [5-7], so the modern BT needs 3D treatment planning as it allows to conform the dose distribution to the target volume and to minimize toxicity to normal tissues.

Historical dose prescription in BT is based on Manchester system that was designed to deliver a specific dose to a reference point (point A) [8], independently of three-dimensional spread of tumour volume. This point has no relationship with tumour position and real threedimensional tumour extent $[9,10]$. Image-based BT treatment planning has been studied using computed tomography (CT) [11-13] or magnetic resonance imaging (MRI) [14].

MRI is considered the best imaging modality for tumour delineation in image-based intracavitary BT [15]; this superiority lies in its better contrast resolution that permits to distinguish tumour from normal uterine, vaginal and other surrounding tissues $[16,17]$ and so, for its properties, is the best choice to define the reference volumes according to (GYN) GEC-ESTRO recommendations (2006) [18]. 18 Fluoro-deoxi-glucose Positron Emission Tomography $\left({ }^{18} \mathrm{~F}-\mathrm{FDG}\right.$ PET) is a functional imaging technique able to visualize the glucose consumption of tissue, that is one of the most represented metabolic pathways of viable neoplastic lesions. For this reason, PET and PET/ CT scan have been studied in radiation treatment planning of different types of tumours [19-21].

In some previously published papers, ${ }^{18} \mathrm{~F}$-FDG PET has been used

*Corresponding author: Fiorentino Sofia Meregalli, MD, Radiation Oncology, San Gerardo Hospital, via Pergolesi 33, 20100 Monza, Italy, Tel: +39(0)392333670; Fax: +39(0)392333414; E-mail: s.meregalli@hsgerardo.org

Received July 30, 2013; Accepted September 21, 2013; Published Septembe 25, 2013

Citation: Meregalli S, Guerra L, Zorz A, Bonetto E, Brenna S, et al. (2013) Intracavitary Brachytherapy in Cervical Carcinoma: The Role of F18-FDG- PET in Treatment Planning. J Nucl Med Radiat Ther S6: 015. doi:10.4172/2155-9619. S6-015

Copyright: @ 2013 Meregalli S, et al. This is an open-access article distributed under the terms of the Creative Commons Attribution License, which permits unrestricted use, distribution, and reproduction in any medium, provided the original author and source are credited. 
for the volume definition of the primary cervical cancer [22] and also in BT plan [10,23-25], but one of the most important shortcoming was the lack of anatomical markers that can make difficult to distinguish physiological uptake of pelvic organs (i.e. ureters, bowel) from that of neoplastic lesions. In this contest the use of hybrid PET/CT scanner, consisting of a PET scanner coupled with a CT scanner on line, could be of help in definition of BT planning in cervical cancer.

Considering these issues, the aim of our feasibility study was to compare the standard CT-based and PET/CT-based clinical target volume (CTV) in BT planning and the assessment of the added benefit of metabolic imaging in BT of cervical cancer.

\section{Materials and Methods}

\section{Patient population}

From June 2007 to May 2010 thirteen women with biopsy proven locally advanced squamous cervical carcinoma were enrolled into the study at the Radiation Oncology Department of San Gerardo Hospital in Monza. Patient characteristics are summarized in table 1. All the patients had whole body PET/CT for staging before treatment. Written informed consent was obtained from all patients.

\section{Radiation therapy and chemotherapy protocol}

All patients underwent external beam radiotherapy to the whole pelvis with a box technique (EBT-1.8 Gy/fraction to a total dose of 50.4 Gy over 6 weeks), with weekly concomitant cisplatin chemotherapy (40 $\mathrm{mg} / \mathrm{m}^{2}$ ). High Dose Rate-BT was performed during the course of pelvic radiation therapy, in order to reduce the total treatment time, starting in the third week of EBT (5 Gy/fraction to 5-6 fractions). A complete vaginal and rectal examination of the clinical extension of the pelvic disease was performed in all the patients before the insertion of the standard Fletcher-Suit tandem. The PET/CT scans were performed and analyzed exclusively in order to produce a simulation of optimized BT plan; all the patients were actually treated under standard conditions.

\section{${ }^{18}$ F-FDG PET/CT Scanning}

Before starting PET/CT scan for BT planning, at the first and the fourth BT fraction (BT1 and BT4) a Fletcher-Suit tandem was positioned in order to simulate the organs position in BT treatment. The patient fastened for 6-8 hours before the scan and blood glucose (cut-off level $170 \mathrm{mg} / \mathrm{dl}$ ) was determined immediately before the tracer administration $(3.7 \mathrm{MBq} / \mathrm{Kg})$. After the tracer administration, intravenous hydration and diuretic agent were administered to reduce the bladder activity. For the scan, a CT $(120 \mathrm{kV}, 80 \mathrm{~mA}, 3.75$ slice thickness) covering the pelvis was performed first, then PET was performed acquiring two bed positions ( 5 minuted/bed) covering the whole pelvis. PET images were reconstructed with iterative algorithm (using commercial software), 128 matrix size, with attenuation, random and scatter correction.

\section{PET based $\left(\mathrm{GTV}_{\mathrm{PET}}\right)$ and $\mathrm{CT}$ based $\left(\mathrm{GTV}_{\mathrm{CT}}\right)$ volume definition}

The transaxial, coronal and sagittal PET/CT images were displayed

\begin{tabular}{|l|l|}
\hline Age $(\boldsymbol{y})$ & $(55 \pm 11) \mathrm{y}$ \\
& Range: $32-68$ y \\
\hline Clinical FIGO Stage & $3 / 13(23 \%)$ IIA \\
& $1 / 13(8 \%)$ IB \\
& $2 / 13(15 \%)$ IIB \\
& $7 / 13(54 \%)$ IIIB \\
\hline Histology & $13 / 13(100 \%)$ Squamous Carcinoma \\
\hline
\end{tabular}

Table 1: Characteristics of 13 patients enrolled into the study.

\begin{tabular}{|c|c|c|c|c|}
\hline & & BT1 & BT4 & $\begin{array}{l}\text { Both } B T \\
\text { fractions }\end{array}$ \\
\hline \multirow[t]{2}{*}{$C T V_{\text {standard }}(\mathrm{ml})$} & Average \pm SD & $(27.9 \pm 9.6)$ & $(23.5 \pm 3.3)$ & $(25.8 \pm 7.5)$ \\
\hline & Range & 15.9-52.3 & 20.4-30.2 & $15.9-52.3$ \\
\hline \multirow{2}{*}{$C T V_{P E T \text {-influenced }}(\mathrm{ml})$} & Average \pm SD & $(22.8 \pm 12.6)$ & $(20.2 \pm 4.6)$ & $(21.6 \pm 9.5)$ \\
\hline & Range & 10.4-57.1 & 13.3-29 & 10.4-57.1 \\
\hline \multirow[t]{2}{*}{$\%$} & Average \pm SD & $(25.1 \pm 32.2) \%$ & $(16.3 \pm 26.8) \%$ & $(20.9 \pm 29.4) \%$ \\
\hline & Range & $2.5 \%-79.7 \%$ & $5.7 \%-0.0 \%$ & $2.5 \%-79.7 \%$ \\
\hline
\end{tabular}

Table 2: Average volume $(\mathrm{ml})$ and range $(\mathrm{ml})$ of $\mathrm{CTV}_{\text {standard }}$ and CTV $\mathrm{PET}_{\text {-influenced }}$ observed in first, in fourth and in both fractions of brachytherapy treatment and percentage differences (\%) between the two volumes (normalized at the average value of the two CTVs).

on a Advantage Windows Workstation (GE Healthcare, Milwaukee, WI-US) with predefined window levels and colour, according internal display protocol for volume definition on PET images. The contouring of the metabolic volume was visually defined on transaxial PET images

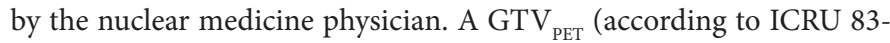
2010) was obtained from each FDG-PET/CT study acquired before $\mathrm{BT}$ fractions for the BT1 and for the BT4. The PET contouring was automatically transferred to the coregistered CT images. These PET/ CT fusion images were then sent to Oncentra Radiation treatment Planning system (Oncentra Masterplan, Nucletron, Veenendaal, The Netherlands), by which the radiation oncologist defined the target volume on the CT images $\left(\mathrm{GTV}_{\mathrm{CT}}\right)$ and, in the same way, critical organs (bladder and rectum).

\section{Clinical Target Volume (CTV) definition}

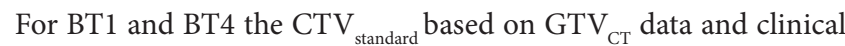
pelvic examination was defined by radiation oncologist first; then the $\mathrm{CTV}_{\text {standard }}$ was reviewed with the inclusion of GTV $\mathrm{PET}_{\text {data. The final }}$ CTV obtained from the overlap of CTV $\mathrm{Ctandard}_{\text {and }} \mathrm{GTV}_{\mathrm{PET}}$ data was called CTV $\mathrm{PET}_{\text {-influenced }}$. For the $2^{\text {nd }}, 3^{\text {rd }}, 5^{\text {th }}$ and $6^{\text {th }}$ BT fraction only the usual CTV $\mathrm{Ctandard}_{\text {inf }}$ was contoured.

\section{Statistical analysis}

$\mathrm{GTV}_{\mathrm{PET}}, \mathrm{CTV}_{\text {standard }}$ and $\mathrm{CTV}_{\mathrm{PET} \text {-influenced }}$ were recorded as absolute values in the $\mathrm{F} 1$ and $\mathrm{F} 4$ groups respectively. Mean \pm standard deviation and range were used to describe these continuous variables. The difference between $\mathrm{CTV}_{\text {standard }}$ and $\mathrm{CTV}_{\text {PET-influenced }}$ were analysed as absolute and percentage values. We compared $\mathrm{CTV}_{\text {standard }}$ and $\mathrm{CTV}_{\text {PET- }}$ with the non-parametric sum rank test and a p-value of 0.05 was considered for statistical significance. A linear regression was applied to evaluate the relation between the different ways of contouring volumes and the Pearson coefficient was considered to summarize the goodness of the model. Stata software 9.0 (Stata Corporation, College Station, Texas, USA) was used for performing statistical analysis.

\section{Results}

All the patients enrolled into this study completed the protocol described above but out of 26 attempts of double CTV definition, only in 21 cases we were able to make a comparison between $\mathrm{CTV}_{\text {standard }}$ and $\mathrm{CTV}_{\text {PET-influenced }}$. In fact for two patients (n.6 and n.7) with PET completely negative at first and fourth BT only $\mathrm{CTV}_{\text {standard }}$ was defined (no informations added from PET). Patient n.3 on BT4 had an uptake in PET images too far from the applicator to be included in the treatment volume, and $\mathrm{CTV}_{\mathrm{PET} \text {-influenced }}$ was considered inappropriate for BT.

The average volumes obtained in each fraction are summarized in Table 2 and details are presented in Table 3. 
Citation: Meregalli S, Guerra L, Zorz A, Bonetto E, Brenna S, et al. (2013) Intracavitary Brachytherapy in Cervical Carcinoma: The Role of F18-FDGPET in Treatment Planning. J Nucl Med Radiat Ther S6: 015. doi:10.4172/2155-9619.S6-015

Page 3 of 5

\begin{tabular}{|c|c|c|c|c|c|c|c|c|c|c|c|c|}
\hline $\mathrm{N}^{\circ}$ & & & & & & & & & BT 4 & & & \\
\hline Pts & $\mathrm{GTV}_{\mathrm{PET}}$ & CTV $_{\text {standard }}$ & $\mathrm{CTV}_{\mathrm{PET} \text {-influenced }}$ & & Volume ${ }^{*}{ }_{P E T}$ & Group & $\mathrm{GTV}_{\mathrm{PET}}$ & $\mathrm{CTV}_{\text {standard }}$ & $\mathrm{CTV}_{\text {PET-influenced }}$ & & Volume $^{*}{ }_{\mathrm{PET}}$ & Group \\
\hline 1 & 16 & 32.4 & 16,0 & $\begin{array}{c}16,4 \\
(67,8 \%)\end{array}$ & $\begin{array}{c}8.0 \\
(24.7 \%)\end{array}$ & A & 18.8 & 30,2 & 18.8 & $\begin{array}{c}11,4 \\
(46,5 \%)\end{array}$ & $\begin{array}{c}6.2 \\
(20.5 \%)\end{array}$ & A \\
\hline 2 & 10.8 & 25.1 & 10,8 & $\begin{array}{c}14,3 \\
(79.7 \%)\end{array}$ & $\begin{array}{c}9.5 \\
(37.8 \%)\end{array}$ & A & 3.4 & 22,2 & 18.8 & $\begin{array}{c}3,4 \\
(16,6 \%)\end{array}$ & $\begin{array}{c}2.9 \\
(13.1 \%)\end{array}$ & C \\
\hline 3 & 86.4 & 52.3 & 57,1 & $\begin{array}{c}-4,8 \\
(-8,8 \%)\end{array}$ & $\begin{array}{c}65.5 \\
(125 \%)\end{array}$ & $\mathrm{E}$ & 15.6 & 33.3 & - & - & $\begin{array}{c}13.8 \\
(41.4 \%)\end{array}$ & C \\
\hline 4 & 25.1 & 27 & 25,9 & $\begin{array}{c}1,1 \\
(4,2 \%)\end{array}$ & $\begin{array}{c}15.8 \\
(58.5 \%)\end{array}$ & C & 7.5 & 25,4 & 24 & $\begin{array}{c}1,4 \\
(5,7 \%)\end{array}$ & $\begin{array}{c}1.8 \\
(7.1 \%)\end{array}$ & D \\
\hline 5 & 3.1 & 17.4 & 10,4 & $\begin{array}{c}7,0 \\
(50,4 \%)\end{array}$ & $\begin{array}{c}1.3 \\
(7.5 \%)\end{array}$ & D & 0.8 & 20,4 & 16.4 & $\begin{array}{c}4,0 \\
(21,7 \%)\end{array}$ & $\begin{array}{c}0 \\
(0 \%)\end{array}$ & D \\
\hline 6 & 0 & 18.8 & - & - & $\begin{array}{c}0 \\
(0 \%)\end{array}$ & $\mathrm{F}$ & 0 & 22,2 & - & - & $\begin{array}{c}0 \\
(0 \%)\end{array}$ & $\mathrm{F}$ \\
\hline 7 & 0 & 25.3 & - & - & $\begin{array}{c}0 \\
(0 \%)\end{array}$ & $\mathrm{F}$ & 0 & 33,6 & - & - & $\begin{array}{c}0 \\
(0 \%)\end{array}$ & $\mathrm{F}$ \\
\hline 8 & 2.7 & 31.7 & 20,8 & $\begin{array}{c}10,9 \\
(41,5 \%)\end{array}$ & $\begin{array}{c}1.2 \\
(3.8 \%)\end{array}$ & B & 1.8 & 27,1 & 21 & $\begin{array}{c}6,1 \\
(25,4 \%)\end{array}$ & $\begin{array}{c}1.4 \\
(5.2 \%)\end{array}$ & B \\
\hline 9 & 1.7 & 26.1 & 26,9 & $\begin{array}{c}-0,8 \\
(-3,0 \%)\end{array}$ & $\begin{array}{c}0.5 \\
(1.9 \%)\end{array}$ & D & 0.3 & 22,3 & 24.7 & $\begin{array}{c}-2,4 \\
(-10,2 \%)\end{array}$ & $\begin{array}{c}0 \\
(0 \%)\end{array}$ & D \\
\hline 10 & 7.5 & 15.9 & 18,8 & $\begin{array}{c}-2,9 \\
(-16,7 \%)\end{array}$ & $\begin{array}{c}6.9 \\
(43.4 \%)\end{array}$ & A & 1.5 & 24,7 & 13.3 & $\begin{array}{c}11,4 \\
(60,0 \%)\end{array}$ & $\begin{array}{c}1.5 \\
(6.1 \%)\end{array}$ & C \\
\hline 11 & 1.2 & 29.3 & 22,3 & $\begin{array}{c}7,0 \\
(27,1 \%)\end{array}$ & $\begin{array}{c}0.1 \\
(0.3 \%)\end{array}$ & D & 0.9 & 20,5 & 29 & $\begin{array}{c}-8,5 \\
(-34,3 \%)\end{array}$ & $\begin{array}{c}0.5 \\
(2.4 \%)\end{array}$ & D \\
\hline 12 & 3.9 & 23.9 & 23,3 & $\begin{array}{c}0,6 \\
(2,5 \%)\end{array}$ & $\begin{array}{c}1.4 \\
(5.9 \%)\end{array}$ & C & 0.5 & 21,5 & 16.9 & $\begin{array}{c}4,6 \\
(24, \%)\end{array}$ & $\begin{array}{c}0 \\
(0 \%)\end{array}$ & D \\
\hline 13 & 6.7 & 25.6 & 18,7 & $\begin{array}{c}6,9 \\
(31,2 \%)\end{array}$ & $\begin{array}{c}4.3 \\
(16.8 \%)\end{array}$ & C & 0.8 & 20,6 & 19.1 & $\begin{array}{c}1,5 \\
(7,6 \%)\end{array}$ & $\begin{array}{c}0.6 \\
(2.9 \%)\end{array}$ & B \\
\hline
\end{tabular}

Table 3: Volume $(\mathrm{ml})$ of $\mathrm{GTV}_{\mathrm{PT}}, \mathrm{CTV}_{\text {standard }}$ and $\mathrm{CTV}$ PET-influenced observed at first and fourth fraction of brachytherapy treatment (BT1 and BT4), differences (\%) between

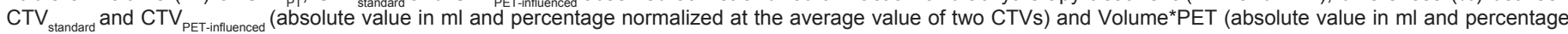
normalized at CTV ${ }_{\text {standard }}$, that is the volume of $\mathrm{GTV}_{\mathrm{PET}}$ that does not intersect with CTV

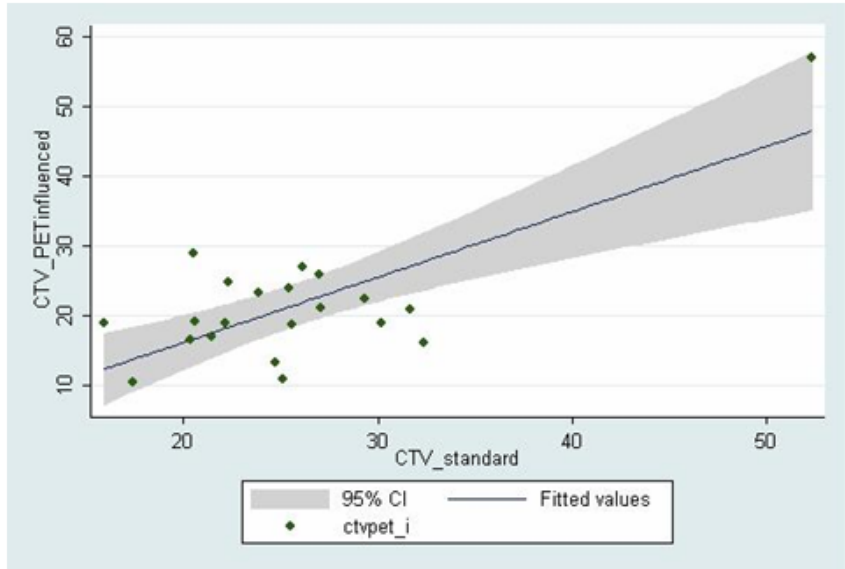

$\mathrm{Y}=0.941 \mathrm{x}-2.692$

$\mathrm{R}^{2}=0.546$

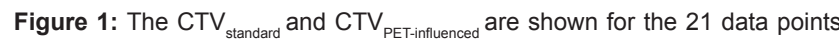
with the best-fit line.

\section{Quantitative comparison of the volumes $\left(\mathrm{CTV}_{\text {standard }} \mathrm{vs}\right.$ CTV PET-influenced )}

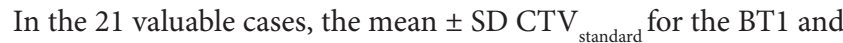
for BT4 were $27.9 \pm 9.6 \mathrm{ml}$ (range: $15.9-52.3 \mathrm{ml}$ ) and $23.5 \pm 3.3 \mathrm{ml}$ (range: 20.4-30.2 ml) respectively. The mean $\pm \mathrm{SD} \mathrm{CTV}_{\mathrm{PET} \text {-influenced }}$ for the BT1 and for BT4 were $22.8 \pm 12.6 \mathrm{ml}$ (range: 10.4-57.1 ml), and $20.2 \pm$ $4.6 \mathrm{ml}$ (range: 13.3-29.0 ml) respectively. Considering both fractions together, the mean $\pm \mathrm{SD} \mathrm{CTV}_{\text {standard }}$ were $25.8 \pm 7.5 \mathrm{ml}$ and the mean \pm SD CTV $\mathrm{PET}_{\text {-influenced }}$ were $21.6 \pm 9.5 \mathrm{ml}$. The difference between the two values is statistically significant with the sum rank test $(\mathrm{p}=0.01)$.
In the 21 cases the absolute difference between the two volumes ranged from 0.6 to $16.4 \mathrm{ml}$. The percentage of difference between the two volumes was normalized at the average value of the two CTVs. In $3 / 21(14.3 \%)$ cases the difference between the two volumes was inferior to $5 \%$, in $3 / 21(14.3 \%)$ the difference was between the $5 \%$ and $10 \%$, in $3 / 21(14.3 \%)$ cases the difference was between $10 \%$ and $20 \%$, and in $12 / 21$ cases $(57.1 \%)$ the difference was $>20 \%$. In $5 / 21$ cases $(23.8 \%)$ $\mathrm{CTV}_{\text {PET-influenced }}$ was greater than $\mathrm{CTV}_{\text {standard }}$, while in $16 / 21$ cases $(76.2 \%)$ were lower than CTV

\section{Analysis of volumes intersection}

In order to evaluate the impact of F18-FDG-PET/CT in defining brachytherapy volume, we have also considered the three-dimensional relative position of the volumes divided into six group (Group A-F Table 3). In 4/26 cases (Table 3: group A) $\mathrm{GTV}_{\mathrm{PET}}$ introduced major variations of the volume of irradiation; because PET/CT detected an uptake area undetectable by clinical visit or CT. The mean absolute value of $\mathrm{GTV}_{\mathrm{PET}}$ that did not intersect with $\mathrm{CTV}_{\text {standard }}$ in these four cases was $7.65 \mathrm{ml}$. The mean percentage of $\mathrm{GTV}_{\mathrm{PET}}$ that did not intersect with CTVstandard (normalized at $\mathrm{CTV}_{\text {standard }}$ ) was $31.6 \%$. In $3 / 26$ cases (Table 3: group B) PET/CT scan slightly modified the volume and the mean absolute value of $\mathrm{GTV}_{\mathrm{PET}}$ that did not intersect with $\mathrm{CTV}_{\text {standard }}$ was $1.07 \mathrm{ml}$. The mean percentage of $\mathrm{GTV}_{\mathrm{PET}}$ that did not intersect with $\mathrm{CTV}_{\text {standard }}$ (normalized at $\mathrm{CTV}_{\text {standard }}$ ) in these three cases was $4.0 \%$.

In 6/26 cases (Table 3: group C) the uptake areas detected by PET/ CT were not covered completely by the applicator's position because too far from the applicator. The stiffness of the applicator is a constrictive factor that may not permit to adequately cover the metabolic area with a hypothetical isodose distribution. In these cases, the mean absolute value of $\mathrm{GTV}_{\mathrm{PET}}$ that did not intersect with $\mathrm{CTV}_{\text {standard }}$ was $6.62 \mathrm{ml}$. The 
mean percentage of GTV $\mathrm{PET}_{\mathrm{PE}}$ that did not intersect with CTVstandard (normalized at $\mathrm{CTV}_{\text {standard }}$ ) was $23.6 \%$.

In $8 / 26$ cases (Table 3: group D) the metabolic positive area was nearly included into the CTVstandard, without additional information by PET/CT. However, the $\mathrm{GTV}_{\mathrm{PET}}$ did not matched with the $\mathrm{CTV}_{\text {st }}$ because the uptake was located in a area smaller than CTV in all these eight cases. In this subgroup the mean absolute value of $\mathrm{GTV}_{\mathrm{PET}}$ that did not intersect with $\mathrm{CTV}_{\text {standard }}$ was $0.53 \mathrm{ml}$. The mean percentage of $\mathrm{GTV}_{\mathrm{PET}}$ that did not intersect with $\mathrm{CTV}_{\text {standard }}$ (normalized at $\mathrm{CTV}_{\text {standard }}$ ) was $2.4 \%$.

In $1 / 26$ cases (Table 3 : group E) the $\mathrm{GTV}_{\mathrm{PET}}$ was considerably larger than the tumour zone identified by CT scan. The CTV $\mathrm{PET}_{\text {-influenced }}$ was majorly modified by PET/CT data, but whole uptake area could not be irradiated because of the limits of the applicator.

In 4/26 cases (Table 3: group F), PET scan was negative without evidence of pathological FDG uptake in the cervix

The different volumes identified by CT and by PET did not overlap in any case.

For the linear regression test, the correlation coefficient is equal to $\mathrm{R}^{2}=0.546$ for the 21 data points (Figure 1 ).

\section{Outcome}

At 3 months after completion of the treatment, all the patients but one underwent a PET/CT which was totally negative for all of them. These are preliminary clinical data with a median follow up of 47 months ( $\mathrm{SD} \pm 14$ months) 10/13 patients are alive, free from disease. Patient n.6 died for intercurrent disease at 3 months from the end of BT. For this patient PET at first and fourth fraction of BT were negative (Table 3: group F).

Two patients had distant failure without pelvic recurrence: patient n.3 (Table 3: group: E-C) had metastasis (lung and peritoneum) after 10 months from the end of BT treated with chemotherapy (DFS 10 months and OS 51 months); patient n.13 (Table 3: group C-B) died for rapidly progressive metastatic disease (bone and Only one patient lomboaortic lymph nodes) after 28 months from the end of the BT (DFS 26 months and OS 28 months). (n 11 Table 3: group D) had a local recurrence (cervix) at 11 month from the end of BT: she was rescued with surgery (DFS 11 month and OS 37 months). The median DFS and OS for all the patients are 44 and 47 months respectively. Acute GI toxicity G1 (RTOG) was recorded, no late GU toxicity was observed.

\section{Discussion}

In cervical carcinoma the tumour volume is one of the most important prognostic factors [5-7]. Brachytherapy is an essential component of definitive radiotherapy of cervical cancer and nowadays needs the integration of 3D imaging: MRI is currently considered the best choice to define the reference volumes according to (GYN) GECESTRO recommendations (2006) $[15,18]$. PET has been considered useful in radiation treatment of cervical cancer, to measure accurately the volume [22], to evaluate tumour volume changes during radiation therapy and to early discriminate good versus bad responders [26,27] . With these new techniques it seems possible to identify individualized volumes for each patients and in theory, for each fraction, to try an improvement of the outcome while reducing the toxicity. Only few dosimetric studies have been conducted about the use of PET in BT planning with similar results. Malapaya [10] compares 2D conventional treatment planning with 3D PET-based treatment planning suggesting that the spread of tumor as shown by PET could make a better coverage of the tumour volume. Lin et al. [23,24] showed that PET-based treatment planning can improve dose coverage without increasing toxicity.

In a more recent feasibility study the Authors reported better results by using PET/CT scan plan than conventional point A [25].

We compared the standard CT-based and the PET/CT-based clinical target volume (CTV) in BT planning to evaluate the role of functional imaging during BT plan in a cohort of patients who were treated under standard conditions.

Comparing the two volumes the percentage difference higher than $20 \%$ between CTV standard $_{\text {and }}$ CTV PET-influeced $_{\text {was in } 57 \% \text { of the total }}$ patients. We found some variable information from PET, in part coherent with clinical and CT data set, in part not coherent; also negative PET in $4 / 26$ studies were found. The absence of FDG uptake in these women could be explained by the early effects of previous EBT: although these data could be of interest for the prognosis of the patients, so far we do not know how this information may be used in the treatment planning. Considering all other cases with a positive PET/CT scan, we observed a statistically significant difference between $\mathrm{CTV}_{\text {PET-influenced }}$ and $\mathrm{CTV}_{\text {standard }}$ considering the mean value of both fractions (Table 2). Our results suggest that a correlation between the two tumour descriptions shows some discrepancies.

In 8 cases the $\mathrm{GTV}_{\mathrm{PET}}$ was included into the $\mathrm{CTV}_{\text {standard }}$ indicating that the two sets of information are coherent but PET information may be only used for an hypothetical adaptive BT. In the other cases, the $\mathrm{GTV}_{\mathrm{PET}}$ was not congruent with clinical pattern and CT information. In these cases the area of FDG-uptake could suggest the opportunity to modify the target volume. Patient $n .3$ had a PET/CT post treatment negative and no recurrence in pelvis was found even if during the two fractions of BT she had at the BT1 an uptake very extended $(86.4 \mathrm{ml})$ and so it was impossible to cover the entire volume of $\mathrm{GTV}_{\mathrm{PET}}$. In a similar situation, according only to the PET information unless a very serious toxicity, we should have to consider a boost of external beam treatment instead of brachytherapy. At BT4 we observed a decrease in the FDG-positive volume but the uptake area was too much lateral and it cannot be reached from the applicator's position. Theoretically these may be considered a very important strategic information. This patient had a progression of disease (peritoneum and lung) treated with chemotherapy but no evidence of disease in pelvis.

In our small patient population, PET information in BT fractions were variable, sometimes suggesting the opportunity to modify the volume to be treated, sometimes congruent with clinical examination and CT information, sometimes negative and sometimes with residual tracer uptake areas often located to far from the applicator and very difficult, if not impossible, to include in the BT planning suggesting another technique of the treatment.

In our limited experience PET scan cannot be used to define target volume as the only source of information but needs integration; nevertheless our results confirm the feasibility of this protocol.

\section{Conclusion}

Because the different possibilities with added PET informations during BT plan, it is very difficult, in our experience, to identify the role of PET in radiation treatment planning of the cervical carcinoma in the phase of intracavitary brachytherapy. But we must consider the 
Citation: Meregalli S, Guerra L, Zorz A, Bonetto E, Brenna S, et al. (2013) Intracavitary Brachytherapy in Cervical Carcinoma: The Role of F18-FDGPET in Treatment Planning. J Nucl Med Radiat Ther S6: 015. doi:10.4172/2155-9619.S6-015

integration of information as an opportunity for the future for a much more individualized treatment.

\section{References}

1. Morris M, Eifel PJ, Lu J, Grigsby PW, Levenback C, et al. (1999) Pelvic radiation with concurrent chemotherapy compared with pelvic and para-aortic radiation for high-risk cervical cancer. N Engl J Med 340: 1137-1143.

2. Rose PG, Bundy BN, Watkins EB, Thigpen JT, Deppe G, et al. (1999) Concurrent cisplatin-based radiotherapy and chemotherapy for locally advanced cervical cancer. N Engl J Med 340: 1144-1153.

3. Keys HM, Bundy BN, Stehman FB, Muderspach LI, Chafe WE, et al. (1999) Cisplatin, radiation, and adjuvant hysterectomy compared with radiation and adjuvant hysterectomy for bulky stage IB cervical carcinoma. N Engl J Med 340: 1154-1161.

4. Thomas GM (2000) Concurrent chemotherapy and radiation for locally advanced cervical cancer: the new standard of care. Semin Radiat Oncol 10: 44-50.

5. Perez CA, Grigsby PW, Nene SM, Camel HM, Galakatos A, et al. (1992) Effect of tumor size on the prognosis of carcinoma of the uterine cervix treated with irradiation alone. Cancer 69: 2796-2806.

6. Eifel PJ, Morris M, Wharton JT, Oswald MJ (1994) The influence of tumor size and morphology on the outcome of patients with FIGO stage IB squamous cell carcinoma of the uterine cervix. Int J Radiat Oncol Biol Phys 29: 9-16.

7. Fyles AW, Pintilie M, Kirkbride P, Levin W, Manchul LA, et al. (1995) Prognostic factors in patients with cervix cancer treated by radiation therapy: results of a multiple regression analysis. Radiother Oncol 35: 107-117.

8. ICRU Report 38 (1985) Dose and Volume Specification for Reporting Intracavitary Therapy in Gynecology. Journal of the 301 ICRU 1985

9. Nag S (2006) Controversies and new developments in gynecologic brachytherapy: image-based intracavitary brachytherapy for cervical carcinoma. Semin Radiat Oncol 16: 164-167.

10. Malyapa RS, Mutic S, Low DA, Zoberi I, Bosch WR, et al. (2002) Physiologic FDG-PET three-dimensional brachytherapy treatment planning for cervical cancer. Int J Radiat Oncol Biol Phys 54: 1140-1146.

11. Pelloski CE, Palmer M, Chronowski GM, Jhingran A, Horton J, et al. (2005) Comparison between CT-based volumetric calculations and ICRU referencepoint estimates of radiation doses delivered to bladder and rectum during intracavitary radiotherapy for cervical cancer. Int J Radiat Oncol Biol Phys 62 $131-137$

12. Kim RY, Shen S, Duan J (2007) Image-based three-dimensional treatment planning of intracavitary brachytherapy for cancer of the cervix: dosevolume histograms of the bladder, rectum, sigmoid colon, and small bowel. Brachytherapy 6: 187-194.

13. van den Bergh F, Meertens $H$, Moonen L, van Bunningen B, Blom A (1998) The use of a transverse CT image for the estimation of the dose given to the rectum in intracavitary brachytherapy for carcinoma of the cervix. Radiother Oncol 47: 85-90.

14. Wachter-Gerstner N, Wachter S, Reinstadler E, Fellner C, Knocke TH, et al. (2003) Bladder and rectum dose defined from MRI based treatment planning for cervix cancer brachytherapy: comparison of dose-volume histograms for organ contours and organ wall, comparison with ICRU rectum and bladder reference point. Radiother Oncol 68: 269-276.

15. Haie-Meder C, Pötter R, Van Limbergen E, Briot E, De Brabandere M, et al. (2005) Recommendations from Gynaecological (GYN) GEC-ESTRO Working
Group (I): concepts and terms in 3D image based 3D treatment planning in cervix cancer brachytherapy with emphasis on MRI assessment of GTV and CTV. Radiother Oncol 74: 235-245.

16. Bipat S, Glas AS, van der Velden J, Zwinderman AH, Bossuyt PM, et al. (2003) Computed tomography and magnetic resonance imaging in staging of uterine cervical carcinoma: a systematic review. Gynecol Oncol 91: 59-66.

17. Choi SH, Kim SH, Choi HJ, Park BK, Lee HJ (2004) Preoperative magnetic resonance imaging staging of uterine cervical carcinoma: results of prospective study. J Comput Assist Tomogr 28: 620-627.

18. Pötter R, Haie-Meder C, Van Limbergen E, Barillot I, De Brabandere M, et al. (2006) Recommendations from gynaecological (GYN) GEC ESTRO working group (II): concepts and terms in 3D image-based treatment planning in cervix cancer brachytherapy-3D dose volume parameters and aspects of 3D imagebased anatomy, radiation physics, radiobiology. Radiother Oncol 78: 67-77.

19. Muijs CT, Schreurs LM, Busz DM, Beukema JC, van der Borden AJ, et al (2009) Consequences of additional use of PET information for target volume delineation and radiotherapy dose distribution for esophageal cancer. Radiother Oncol 93: 447-453.

20. Mutic S, Malyapa RS, Grigsby PW, Dehdashti F, Miller TR, et al. (2003) PETguided IMRT for cervical carcinoma with positive para-aortic lymph nodes-a dose-escalation treatment planning study. Int J Radiat Oncol Biol Phys 55: 2835 .

21. Spratt DE, Diaz R, McElmurray J, Csiki I, Duggan D, et al. (2010) Impact of FDG PET/CT on delineation of the gross tumor volume for radiation planning in non-small-cell lung cancer. Clin Nucl Med 35: 237-243.

22. Miller TR, Grigsby PW (2002) Measurement of tumor volume by PET to evaluate prognosis in patients with advanced cervical cancer treated by radiation therapy. Int J Radiat Oncol Biol Phys 53: 353-359.

23. Lin LL, Mutic S, Malyapa RS, Low DA, Miller TR, et al. (2005) Sequential FDG$\mathrm{PET}$ brachytherapy treatment planning in carcinoma of the cervix. Int J Radiat Oncol Biol Phys 63: 1494-1501.

24. Lin LL, Mutic S, Low DA, LaForest R, Vicic M, et al (2007) Adaptive brachytherapy treatment planning for cervical cancer using FDG-PET. Int $J$ Radiat Oncol Biol Phys 67: 91-96.

25. Nam H, Huh SJ, Ju SG, Park W, Lee JE, et al. (2012) 18F-fluorodeoxyglucose positron emisson tomography/computed tomography guided conformal brachytherapy for cervical cancer. Int J Radiat Oncol Biol Phys 84: e29-34.

26. Lin LL, Yang Z, Mutic S, Miller TR, Grigsby PW (2006) FDG-PET imaging for the assessment of physiologic volume response during radiotherapy in cervix cancer. Int J Radiat Oncol Biol Phys 65: 177-181.

27. Grigsby PW, Siegel BA, Dehdashti F, Rader J, Zoberi I (2004) Posttherapy $\left[{ }^{18} \mathrm{~F}\right]$ fluorodeoxyglucose positron emission tomography in carcinoma of the cervix: response and outcome. J Clin Oncol 22: 2167-2171.
This article was originally published in a special issue, Cancer Radiation Therapy handled by Editor(s). Dr. Xin Chen, University of Arkansas for Medical Sciences, USA 